\title{
Mirror control of responding on fixed-ratio schedules in pigeons*
}

\author{
PERRIN S. COHEN and THOMAS A. LOONEY \\ Northeastern University, Boston, Massachusetts 02115
}

\begin{abstract}
One of three pigeons exposed to multiple FR FR reinforcement schedules attacked a mirror target during postreinforcement pauses preceding the higher fixed ratio schedule. The same mirror-image stimulation, on the other hand, reduced reinforcement rate for all three pigeons by selectively increasing postreinforcement pauses preceding the higher fixed ratio schedule. This indicates that in studies of reinforcement schedules with pigeons, mirror-image stimulation from surfaces commonly present in standard test chambers (e.g., one-way mirrors, metal walls) may interact with schedule parameters to control postreinforcement behavior other than attack.
\end{abstract}

Knutson (1970) and Cohen and Looney (1973) demonstrated that when pigeons are exposed to fixed ratio (FR) schedules of reinforcement for keypecking in the presence of a live pigeon, stuffed pigeon, or mirror, the target controlled attack as well as other unspecified behaviors during the postreinforcement pauses ( $\left.P^{R} \mathbf{P}\right)$. In both experiments, when the target was removed from the chamber so that attack could not occur, there was a decrease in $\mathrm{PS}^{\mathrm{R}} \mathrm{Ps}$ that was not due entirely to the elimination of the time engaged in attacking the target.

Studies concerned with schedule-induced attack have demonstrated that the percentage of pigeons that exhibit such attack depends in part upon the type of target employed. Azrin, Hutchinson, and Hake (1966) have reported that all pigeons attacked a live target during extinction following exposure to a continuous reinforcement schedule; whereas, only $25 \%$ attacked a stuffed target under the same conditions. Similarly, Cohen and Looney (1973) found that over a wide range of FR schedules, only two out of three experimentally naive pigeons exhibited sustained attack on a mirror. In short, schedule-induced attack does not necessarily occur on inanimate targets under schedule conditions that reliably induce attack on a live target. The present study determined whether a mirror would control unspecified postreinforcement pause behaviors under conditions in which it failed to control attack.

\section{METHOD}

\section{Subjects}

Three experimentally naive White Carneaux pigeons from Palmetto Pigeon Plant, were maintained at $80 \%( \pm 15 \mathrm{~g})$ of their free feeding weights. They were approximately 1 year old at the start of the experiment and were housed in individual home cages under constant illumination.

\section{Apparatus}

A $31.5 \times 35.3 \times 25.3 \mathrm{~cm}$ operant pigeon chamber with a

*This research was conducted at Florida State University and was supported, in part, by Psychobiology Research Center grants (United States Public Health Service Grants NB-7468 and MH-11218 and National Science Foundation Grant GU-2612) and Biomedical Sciences Support Grant to Northeastern University (DHEW 3505R R07143-0251). T.A.L. was supported by National Science Foundation Traineeship Grant No. G7-1975. Reprints may be obtained from Perrin S. Cohen, Department of Psychology, 440 United Realty, Northeastern University, Boston, Massachusetts 02115.
Lehigh Valley Electronics two-key intelligence panel was used. Only the response key to the left of the grain hopper was operative. This key was transilluminated with either a green or white light and had a minimum force requirement for operation of $0.15 \mathrm{~N}$, as measured by a Jonard dynamometer. A 12.8-cm-wide, 30.2-cm-high, and .23-cm-thick mirror was mounted on the side wall closest to the response key (see Cohen \& Looney, 1973). The distance between the edge of the mirror closest to the intelligence panel and the intelligence panel itself was $17 \mathrm{~cm}$. The centers of the response key and the food hopper were 11.4 and $17.8 \mathrm{~cm}$, respectively, from the wall on which the mirror was mounted. With this arrangement, the pigeon neither brushed against the mirror nor was reflected in it while pecking the response key. Chamber illumination was provided by six 1.6-W hou selights mounted on the roof of the chamber behind a ground glass shield. A wide-angle peephole was mounted on the chamber door, and a blower provided ventilation and masking noise. Experimental contingencies and recordings were scheduled by a system of relays, counters, and timers in an adjacent room.

\section{Procedure}

Responding on a white key was hand shaped and maintained by a continuous reinforcement schedule. Reinforcement was defined as 3-sec access to grain from the hopper. All sessions were terminated after either 60 food presentations or $90 \mathrm{~min}$, whichever occurred first. After the FR schedule of reinforcement for keypecking was gradually increased to FR 10 over 30 sessions, the mirror target was introduced into the chamber. In the presence of the mirror, the Ss were first exposed to a series of FR schedules for a minimum of 70 sessions and then to multiple FR FR reinforcement schedules. The multiple schedules consisted of a fixed FR-25 component in the presence of a white keylight and a second FR schedule which varied across sessions in the presence of a green keylight. One food presentation in the presence of the white keylight alternated with one food presentation in the presence of the green light. After 10 sessions with FR 25 FR 25, the FR schedule in the presence of the green keylight was increased by 25 if all 60 food presentations had been delivered during the last five sessions. Following 10 sessions on the new schedule, the varied FR was again increased by 25 if all 60 food presentations were delivered within the $90-\mathrm{min}$ time limit during the last five sessions. This procedure was continued for each pigeon until the $S$ did not meet the criterion for increasing the varied FR schedule component. Each pigeon was then exposed to 30-38 additional sessions on its final multiple FR FR schedule. This was a multiple FR 25 FR 125, FR 25 FR 75, and FR 25 FR 200 schedule for Pigeon 4964, Pigeon 4270, and Pigeon 771, respectively. During this phase, the mirror was alternately uncovered and covered with a piece of brown construction paper over five to seven successive blocks of four to five sessions each. 


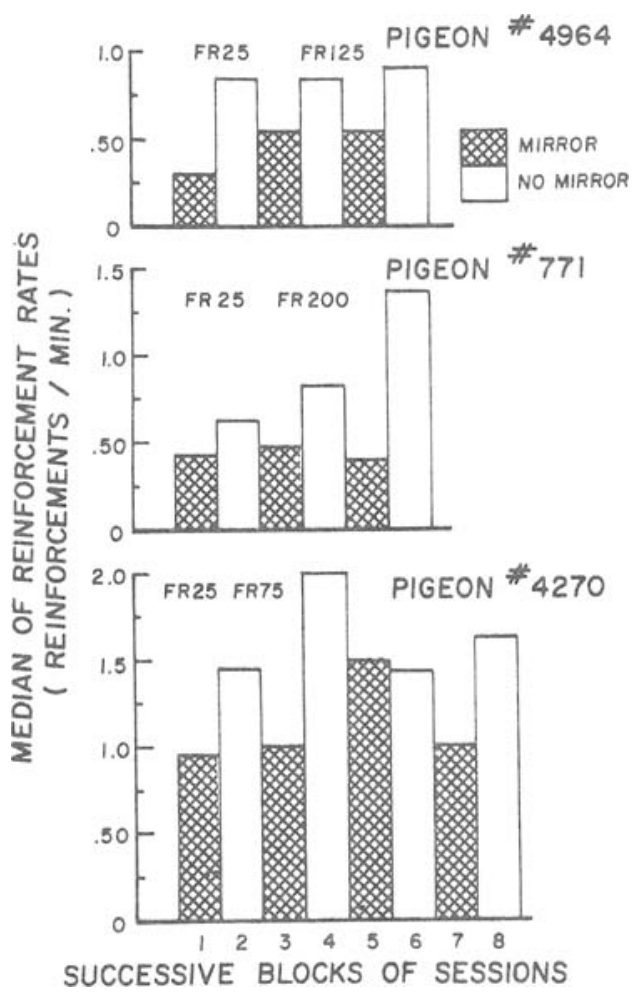

Fig. 1. Median reinforcement rates (reinforcements/min) over successive blocks of 4-5 sessions in which the mirror was alternately uncovered and covered for Pigeon 4964, Pigeon 771, and Pigeon 4270.

\section{RESULTS AND DISCUSSION}

Pigeon 4964 was the only pigeon that showed sustained attack on the mirror target during exposure to the FR and multiple FR FR schedules. As was found in a previous study with multiple FR FR schedules (Cohen \& Looney, 19.73), this $S$ attacked the mirror during the stimulus correlated with the higher FR schedule. During the final phase in which the mirror was alternately uncovered and covered over blocks of sessions, only Pigeon 4964 had a higher rate of target responding when the mirror was uncovered than when it was covered. For that pigeon, median overall rate of attack was 1.83 responses/min (range across sessions of .76-3.87) with the mirror uncovered and a median of .02 responses/min (range across sessions of $0-.12$ ) with the mirror covered. Pigeon 771 and Pigeon 4270, on the other hand, had median rates of .04 responses $/ \mathrm{min}$ (range across sessions of .01-.24) and .10 (range across sessions of $0-.62$ ), respectively, for sessions in which the mirror was uncovered and .03 responses/min (range across sessions of $0-.08$ ) and .06 responses/min (range across sessions of $0-.14$ ) for sessions in which the mirror was covered.

Figure 1 shows the median reinforcement rates for successive blocks of sessions in which the mirror was alternately uncovered and covered. In spite of the fact that mirror-image stimulation controlled target responding for only one pigeon (Pigeon 4964), it reduced reinforcement rate on the multiple FR FR schedule for all three Ss.

The sequential pattern of key and mirror responding on multiple FR FR schedules for sessions in which the mirror was uncovered and covered is shown for all pigeons in Fig. 2. The cumulative records in this figure were obtained during the final session of the last exposure to the mirror and no-mirror conditions. Cumulative number of key responses are plotted as a function of session time with each downward deflection of the pen corresponding to one mirror response. The recorder reset following the completion of the longer FR component. This figure demonstrates that the decrease in reinforcement rate that occurred during exposure to the mirror (Fig. 1) was due entirely to an increase in the $\mathrm{PS}^{\mathrm{R}} \mathbf{P}$ in the presence of the discriminative stimulus $\left(\mathrm{S}^{\mathbf{D}}\right)$ correlated with the higher FR schedule. There is no evidence for any pigeon that mirror-image stimulation either disrupted keypecking during the FR runs or increased $\mathrm{PS}^{\mathrm{R}} \mathrm{Ps}$ in the presence of the $\mathrm{S}^{\mathrm{D}}$ correlated with the lower FR schedule. As was the case with live pigeon targets in Knutson's study (1970), and with a mirror target in Cohen and Looney's (1973) study, this increase in $\mathrm{PS}^{\mathrm{R}} \mathrm{Ps}$ for Pigeon 4964 was not due exclusively to the additional time spent in attacking the target. In addition, Knutson (1970) also found that presentation of a live target influenced the S's postreinforcement behaviors as an increasing function of the FR requirement.

The fact that the mirror target controlled attack and increased $P^{R} P s$ preceding the long $F R$ run for Pigeon 4964 is a replication of a previous finding (Cohen \& Looney, 1973). The results for the two "nonattacking" pigeons in this study, on the other hand, demonstrate that an inanimate target can control postreinforcement behavior on an FR schedule independently of the occurrence of attack. Observations of these pigeons during sessions in which the mirror was present indicated that both Ss engaged in stereotyped idiosyncratic behaviors during the $\mathrm{PS}^{\mathrm{R}} \mathrm{P}$ preceding the long FR run. For Pigeon 4270, this consisted of pecking the ceiling in the areas between the mirror target and response key for as long as 10 consecutive minutes. Pigeon 771, on the other hand, stood in front of the mirror facing it during the $\mathrm{PS}^{\mathbf{R}} \mathrm{P}$ preceding the longer FR run. For both birds, the same stereotyped postreinforcement pause behavior persisted within and across experimental sessions with the mirror present. Although the differential schedule control of these stereotyped behaviors as well as their temporal patterning and stability strongly suggest that they were schedule induced "adjunctive" (Falk, 1971) or "interim" (Staddon \& Simmelhag, 1971) behaviors, one cannot rule out the possibility that they would have occured in the absence of the reinforcement schedule 


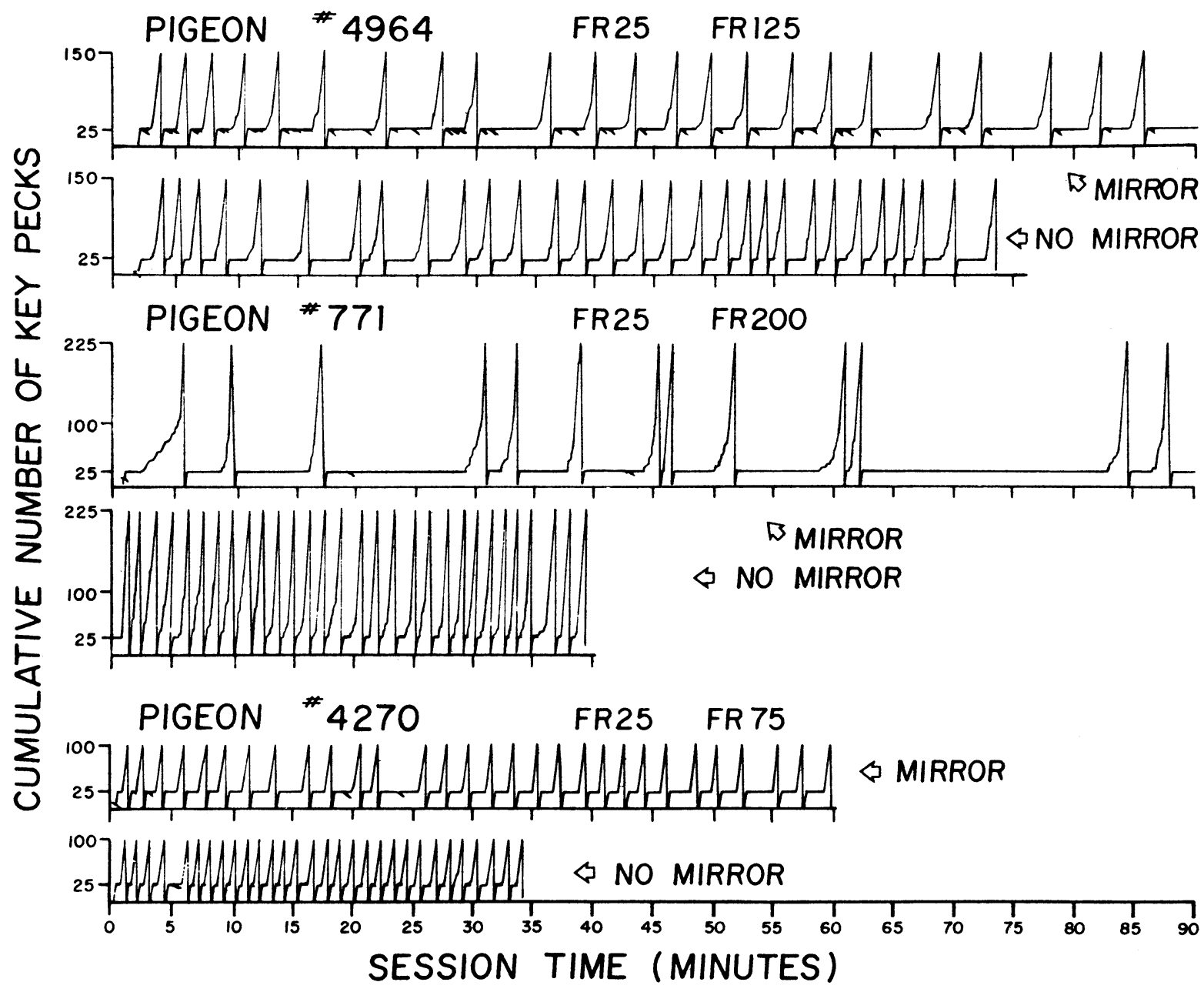

Fig. 2. Cumulative number of keypecks plotted as a function of session time (minu tes) for the final session of the last exposure to the mirror and no-mirror conditions for Pigeon 4964, Pigeon 771, and Pigeon 4270. Each downward deflection of the pen corresponds to one mirror response and the recorder reset following the completion of the longer FR component of the multiple schedule.

(Gallup, 1968). Subsequent research designed to examine species-specific behavior of pigeons to mirror-image stimulation alone will answer this question.

Although these results demonstrate that mirror-image stimulation can control postreinforcement pause behaviors on certain FR schedules independently of the occurrence of attack, it is not clear what aspect of the mirror target was the controlling variable. Additional research with "attackers" and "nonattackers" using inanimate targets such as photographs and drawings (Looney \& Cohen, 1974) will examine that question.

Cohen and Looney (1973) cautioned that, in studies of reinforcement schedules with pigeons, reflective surfaces commonly present in standard operant test chambers, such as metal walls and one-way mirrors, may gain control over attack on those surfaces. The results of this study raise the additional possibility that even in those situations where responses do not come in contact with a reflective surface, the surface may interact with schedule parameters to control other stereotyped idiosyncratic behaviors.

\section{REFERENCES}

Azrin, N. H., Hutchinson, R. R., \& Hake, D. F. Extinction-induced aggression. Journal of the Experimental Analysis of Behavior, 1966, 9, 191-204.

Cohen, P. S. \& Looney, T. A. Schedule-induced mirror responding in the pigeon. Journal of the Experimental Analysis of Behavior, 1973, 19, 395-408.

Falk, J. R. The nature and determinants of adjunctive behavior. Physiology \& Behavior, 1971, 6, 577-588.

Flory, R. K. Attack behavior in a multiple fixed-ratio schedule of reinforcement. Psychonomic Science, 1969, 16, 156-157. Gallup, G. G., Jr. Mirror-image stimulation. Psychological Bulletin, 1968, 70, 782-793.

Knutson, J. F. Aggression during the fixed-ratio and extinction components of a multiple schedule of reinforcement. Journal of the Experim ental Analysis of Behavior, 1970, 13, 221-231.

Looney, T. A., \& Cohen, P. S. Pictorial target control of schedule-induced attack in White Carneaux pigeons. Journal of the Experimental Analysis of Behavior, 1974, 21, 571-584.

Staddon, J. E. R., \& Simmelhag, V. L. The "superstition" experiment: A reexamination of its implications for the principles of adaptive behavior. Psychological Review, 1971, 78, 3-43.

(Received for publication April 15, 1974.) 